\title{
Ku can contribute to telomere lengthening in yeast at multiple positions in the telomerase RNP
}

\author{
DAVID C. ZAPPULLA, ${ }^{1}$ KAREN J. GOODRICH, ${ }^{2}$ JULIAN R. ARTHUR, ${ }^{3}$ LISA A. GURSKI, ${ }^{3}$ \\ ELIZABETH M. DENHAM, ${ }^{3}$ ANNE E. STELLWAGEN, ${ }^{3}$ and THOMAS R. CECH ${ }^{2}$ \\ ${ }^{1}$ Department of Biology, Johns Hopkins University, Baltimore, Maryland 21218, USA \\ ${ }^{2}$ Howard Hughes Medical Institute, Department of Chemistry and Biochemistry, University of Colorado, Boulder, Colorado 80309, USA \\ ${ }^{3}$ Department of Biology, Boston College, Chestnut Hill, Massachusetts 02467, USA
}

\begin{abstract}
Unlike ribonucleoprotein complexes that have a highly ordered overall architecture, such as the ribosome, yeast telomerase appears to be much more loosely constrained. Here, we investigate the importance of positioning of the Ku subunit within the 1157-nt yeast telomerase RNA (TLC1). Deletion of the 48-nt Ku-binding hairpin in TLC1 RNA (tlc1 $\Delta 48$ ) reduces telomere length, survival of cells with gross chromosomal rearrangements, and de novo telomere addition at a broken chromosome end. To test the function of $\mathrm{Ku}$ at novel positions in the telomerase RNP, we reintroduced its binding site into tlc1 $\Delta 48$ RNA at position 446 or 1029. We found that Ku bound to these repositioned sites in vivo and telomere length increased slightly, but statistically significantly. The ability of telomerase to promote survival of cells with gross chromosomal rearrangements by healing damaged chromosome arms was also partially restored, whereas the kinetics of DNA addition to a specific chromosome break was delayed. Having two Ku sites in TLC1 caused progressive hyperelongation of a variable subset of telomeres, consistent with $\mathrm{Ku}^{\prime} \mathrm{s}$ role in telomerase recruitment to chromosome ends. The number of Ku-binding sites in TLC1 contributed to telomerase RNA abundance in vivo but was only partially responsible for telomere length phenotypes. Thus, telomerase RNA levels and telomere length regulation can be modulated by the number of Ku sites in telomerase RNA. Furthermore, there is substantial flexibility in the relative positioning of Ku in the telomerase RNP for native telomere length maintenance, although not as much flexibility as for the essential Est1p subunit.
\end{abstract}

Keywords: RNA; telomerase; TLC1; Ku; flexible scaffold; yeast

\section{INTRODUCTION}

X-ray crystallography has led to high-resolution structure determination of macromolecular assemblies that are well ordered. As a consequence, precisely determined structures such as those of the nucleosome and the ribosome have become archetypes for how one tends to envision nucleic acid-protein complexes (Luger et al. 1997; Moore and Steitz 2002). However, some other complexes of nucleic acid and protein, even including essential ones and those harboring a separate (structured) enzymatic domain, appear to be highly flexible (Zappulla and Cech 2006). For example, the telomerase RNA in yeast appears to provide a functionally and potentially physically flexible scaffold, or

Reprint requests to: David C. Zappulla, Department of Biology, Johns Hopkins University, Baltimore, MD 21218, USA; e-mail: zappulla@jhu. edu; fax: (410) 516-5213.

Article published online ahead of print. Article and publication date are at http://www.rnajournal.org/cgi/doi/10.1261/rna.2483611. tether, for the essential Est1 (Ever Shorter Telomeres 1) protein subunit (Zappulla and Cech 2004).

Telomerase is the enzyme that replenishes DNA at the ends of eukaryotic chromosomes, a function that is beyond the ability of the conventional semiconservative DNA replication machinery (Watson 1972; Olovnikov 1973; Greider and Blackburn 1989; Lingner et al. 1995). Because maintaining telomeric DNA is required for cell proliferation and preventing gene loss, regulation of telomere replication is of fundamental importance in cancer and a growing list of degenerative diseases. In the budding yeast Saccharomyces cerevisiae the telomerase RNA subunit provides the template for synthesis of telomeric DNA as well as binding sites for at least four proteins or protein complexes: Est2p, Est1p, the Ku heterodimer, and the Sm heteroheptamer (see Fig. 1; Singer and Gottschling 1994; Cech 2004). Est $2 p$ is the telomerase reverse transcriptase (TERT) catalytic subunit in yeast. Est2p interacts with the template nucleotides, which it reverse transcribes to synthesize DNA, and it binds in the vicinity of a pseudoknot/triple-helix 


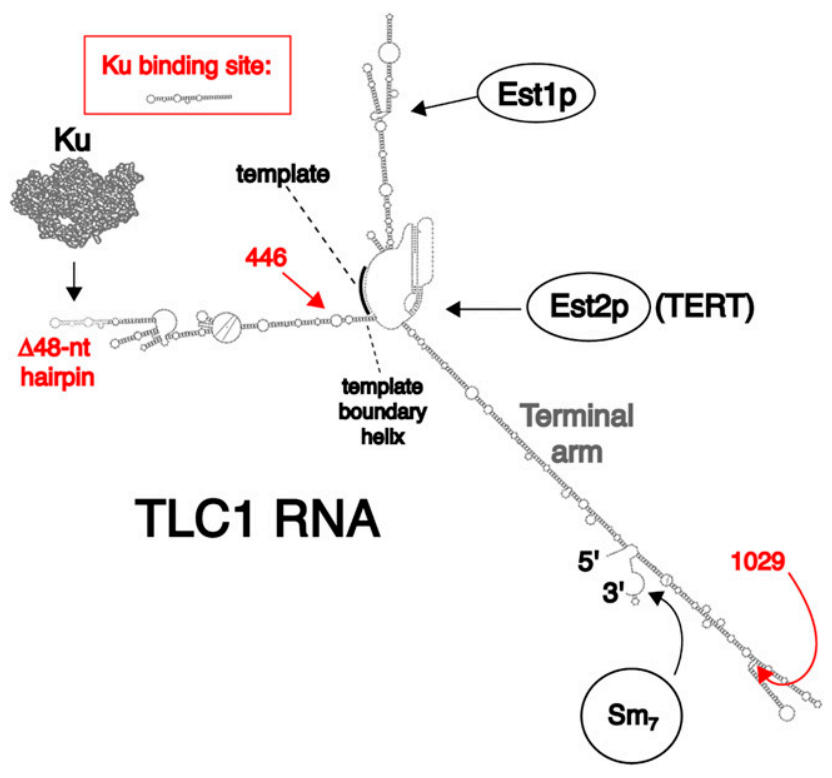

FIGURE 1. Schematic of Ku site deletion and reintroduction in the context of the TLC1 secondary structure model. The 48 nucleotides in TLC1 required for Ku-binding are shown in light gray (" $\Delta 48$-nt hairpin") next to the crystal structure for the highly conserved $\mathrm{Ku}$ heterodimer (Walker et al. 2001). The Mfold-predicted structure of the 74-nt Ku-binding site that was introduced at position 446 or 1029 is in the red box. The TLC1 model displayed is identical to the mature form published in Zappulla and Cech (2004), except that the pseudoknot (with three base-triple interactions) is also now incorporated (Lin et al. 2004; Qiao and Cech 2008) and the 5' end begins 10 nucleotides further $3^{\prime}$ to reflect the more accurate end determined by Dandjinou et al. (2004).

structure in the central core region of telomerase RNA (Livengood et al. 2002; Tzfati et al. 2003; Chappell and Lundblad 2004; Dandjinou et al. 2004; Lin et al. 2004; Theimer et al. 2005). The RNA triple-helix also contributes to telomerase catalysis (Qiao and Cech 2008). In yeast as in other systems, TERT plus the RNA subunit are necessary and sufficient for reconstituting telomerase activity in reticulocyte lysates (Zappulla et al. 2005). The proposed TLC1 secondary structure models show the template and Est2pbinding regions in close proximity within the central core region, whereas the binding sites for accessory proteins exist near the tips of three long, partially helical arms (Dandjinou et al. 2004; Zappulla and Cech 2004).

Previous experiments have shown that large single deletions spanning the majority of the 1157-nt TLC1 RNA are tolerated in vivo (Livengood et al. 2002). Furthermore, Mini-TLC1 RNAs as small as one-third the size of wild type (384 nucleotides; smaller than the 451-nt human RNA) allow yeast to maintain short telomeres and avoid senescence (Zappulla et al. 2005). The regions of TLC1 that are dispensable are very poorly conserved, even among closely related species (Tzfati et al. 2003; Dandjinou et al. 2004; Zappulla and Cech 2004). This is quite different from most other RNPs essential for cellular proliferation. However, certain budding yeast snRNAs are also larger than their homologs in other organisms, and much of their sequence is also dispensable for essential function (Igel and Ares 1988; Shuster and Guthrie 1988; Siliciano et al. 1991). The longer arms in natural TLC1 relative to Mini-T do provide better RNA accumulation and a significant fitness increase (Zappulla et al. 2005), which presumably contributes to the evolutionary selection of the larger RNA in nature.

The sum of these observations led to the hypothesis that TLC1 functions as a flexible RNA scaffold for the protein subunits (Evans and Lundblad 2002; Livengood et al. 2002). This hypothesis was substantiated for the Estlp essential accessory subunit: When the Est1p-binding nucleotides 514694 were relocated to positions 211, 446, or 1029 (new numbering reflects $5^{\prime}$ end reported by Dandjinou et al. 2004), telomerase retained its ability to maintain telomere length in vivo (Zappulla and Cech 2004).

The Ku heterodimer is best known for its role in DNA repair (Boulton and Jackson 1996; Peterson et al. 2001; Stellwagen et al. 2003; Fisher and Zakian 2005; Ting et al. 2005). Ku binds directly to a variety of DNA structures in vitro, but interacts with the ends of DNA with highest affinity and is essential for nonhomologous end-joining (NHEJ) (Mimori and Hardin 1986; Boulton and Jackson 1996; Tuteja and Tuteja 2000). Seemingly paradoxically, Ku also binds natural chromosome ends, where it is part of the protective heterochromatin-like structure that protects against end joining. In yeast, $\mathrm{Ku}$ binds telomerase RNA via a stem-loop, or "hairpin," structure (Stellwagen et al. 2003) and it has also been reported to bind the human telomerase RNA (Ting et al. 2005). Yeast telomerase RNA was first identified for its ability to disrupt telomeric silencing by binding $\mathrm{Ku}$ when overexpressed from a galactose-inducible promoter (Singer and Gottschling 1994). Yeast lacking Ku subunits or the 48-nt Ku-binding hairpin in TLC1 (tlc1 $\Delta 48$ ) have similarly short but stable telomeres and do not senesce (Peterson et al. 2001). Telomeres retain full $\mathrm{Ku}$-association in the $t l c 1 \Delta 48$ strain, despite the loss of the Ku-TLC1 interaction (Fisher et al. 2004). Cells deleted for YKU80, YKU70, or both genes are temperature sensitive, arresting in $\mathrm{G}_{2} / \mathrm{M}$ at $37^{\circ} \mathrm{C}$ (Feldmann and Winnacker 1993; Feldmann et al. 1996). This arrest is probably due to the triggering of a DNA damagerelated checkpoint caused by extensive resection of the $5^{\prime}$ end of the chromosomes in the absence of Ku (Gravel et al. 1998).

In addition to its canonical role, telomerase also adds telomere sequence to broken chromosome ends (for review, see Pennaneach et al. 2006). This low-frequency event can promote survival of cells with gross chromosomal rearrangements (GCRs), as telomere addition to a broken chromosome leads to loss of the distal portion, but survival of the cell if this chromosomal fragment contains no essential gene. This process is mediated in yeast in large part by $\mathrm{Ku}$, which binds efficiently to broken DNA ends and to telomerase RNA, as detailed above.

Here, we first examine the effects of repositioning $\mathrm{Ku}$ in the telomerase RNP on telomere length maintenance and 
find that the $\mathrm{Ku}$ subunit retains at least partial function even when tethered to telomerase RNA through alternative positions. A second largely binding position-independent function of $\mathrm{Ku}$ is its contribution to telomerase RNA abundance. In contrast, TLC1 alleles with repositioned $\mathrm{Ku}$ sites do not perform as well at promoting telomerase-mediated healing of broken chromosome ends. These results extend and refine the model of yeast telomerase RNA as a flexible scaffold for protein binding.

\section{RESULTS}

\section{Targeting Ku to alternative positions in the yeast telomerase RNP}

To determine the importance of the position of $\mathrm{Ku}$ in the telomerase ribonucleoprotein complex, we relocated the $\mathrm{Ku}$ binding hairpin in the 1157-nt TLC1 RNA to two different positions (Fig. 1). The Ku-binding site normally follows nucleotide 278 of TLC1, and we moved it to either 446 or 1029. To predict whether the $\mathrm{Ku}$ site would fold properly when inserted elsewhere in TLC1, we used Mfold software (Mathews et al. 1999; Zuker 2003) to assist in our design (Supplemental Fig. 1). This led us to insert a 74-nt Ku site (nucleotides 262-335; see red box in Fig. 1; Supplemental Fig. 1A), which includes the 48-nt hairpin shown to be sufficient for binding (Stellwagen et al. 2003) as well as the additional 5' and $3^{\prime}$ nucleotides that are paired beyond the base of its stem.

We first addressed the important question of whether the relocated sites in TLC1 bind to $\mathrm{Ku}$ in vivo. We took advantage of the assay that first identified TLC1 (Singer and Gottschling 1994; Singer et al. 1998), which is based on the fact that overexpression of TLC1 RNA competes with telomeric DNA for binding $\mathrm{Ku}$ (Singer and Gottschling 1994; Peterson et al. 2001; Stellwagen et al. 2003), leading to a readily detectable loss of transcriptional silencing (i.e., telomere position effect, TPE). As expected, when wildtype TLC1 RNA was overexpressed from the galactoseinducible GAL1/10 promoter, telomeric silencing was disrupted (Fig. 2A). This effect depended on the 48-nt Ku-binding hairpin in TLC1 (Fig. 2B, tlc1 $\Delta 48$ ). When we overproduced TLC1 RNAs with the $\mathrm{Ku}$ site relocated to position 446 or 1029 , we observed silencing disruption as with wild-type TLC1, at least 100-fold more than with tlc1 $\Delta 48$ or vector alone and slightly less than with an RNA with three tandem $\mathrm{Ku}$ sites (Fig. 2B). This result indicates that $\mathrm{Ku}$ binds very similarly to TLC1 in vivo when its binding site is repositioned compared with when it is at its native position.

\section{Repositioned Ku in the telomerase RNP still contributes to maintaining telomere length}

We transformed yeast cells that have the telomerase RNA gene deleted $(t l c 1 \Delta)$ with low copy-number centromere-

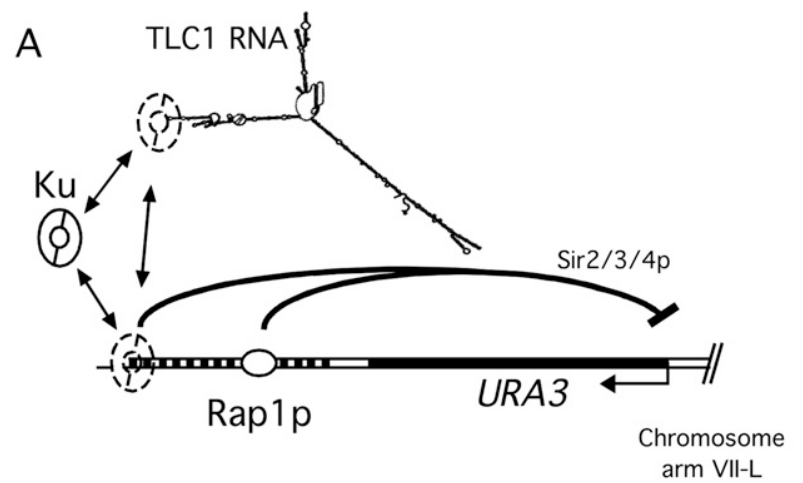

B

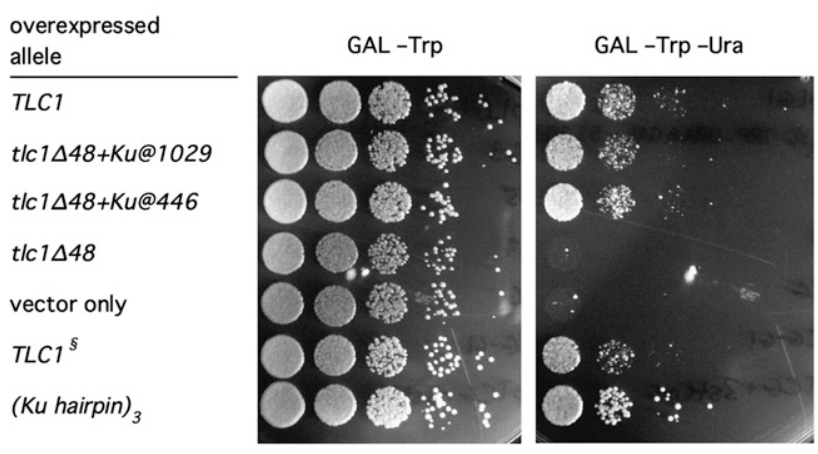

FIGURE 2. Ku binds to repositioned sites in TLC1 RNA in vivo. (A) TLC1 overexpression disrupts telomeric silencing by binding to $\mathrm{Ku}$ (Singer and Gottschling 1994; Peterson et al. 2001). The telomere shown is the left arm of chromosome VII in strain UCC3505 (Singer and Gottschling 1994), where the URA3 gene has been introduced nearby as a reporter for telomeric silencing. (Black and white boxes) Telomeric DNA repeats. (Sir2/3/4p) The Sir2p/Sir3p/Sir4p transcriptional silencing complex that is recruited by $\mathrm{Ku}$ and Raplp to DNA and spreads to subtelomeric regions. (B) Ku binds to TLC1 when its binding site is repositioned in the RNA. Ku binding by TLC1 RNAs was assessed by the ability of various GAL-overexpressed TLC1 alleles to disrupt telomeric silencing of a URA3 reporter gene. Tenfold serial dilutions of yeast transformants expressing the indicated TRP1marked plasmid-borne alleles were spotted onto GAL -Trp as a control for concentration of viable cells in the cultures and onto GAL -Trp -Ura to assess the extent of silencing disruption of the telomere-proximal URA3 reporter gene. [(Ku hairpin $\left.)_{3}\right]$ Triple tandem $\mathrm{Ku}$ site that is a particularly potent anti-silencing construct. $\left(T L C 1^{\S}\right)$ Wild-type TLC1 expression plasmid used in previous studies (Singer and Gottschling 1994; Peterson et al. 2001; Stellwagen et al. 2003).

containing plasmids harboring TLC1 alleles with different $\mathrm{Ku}$ sites and arrangements. After shuffling out a wild-type TLC1 cover plasmid and passaging cells in liquid culture, we isolated genomic DNA, digested it with XhoI, and performed Southern blot hybridization with a telomeric probe. Hybridization to an internal fragment of chromosome IV provided a standard for relative electrophoretic mobility. We developed a method for identifying weighted average telomere length from even a non-Gaussian distribution of fragments (see Materials and Methods). $\mathrm{Y}^{\prime}$ element-containing telomeric restriction fragments (17 of these are predicted from the Saccharomyces genome 
database) have a broad size distribution, which we determined to have an average length of $1267 \pm 7$ bp in cells expressing wild-type TLC1 RNA. (Comparing this value with the genomic database suggests that the average amount of telomeric sequence for $\mathrm{Y}^{\prime}$ telomeres in the cells used in this experiment is $171 \mathrm{bp}$.) Average $\mathrm{Y}^{\prime}$ telomere length of senescing $t l c 1 \Delta$ cells (containing vector only), harvested between 50 and 70 generations after loss of TLC1, was decreased by $139 \pm 12$ bp (see Table 1 , first column). In contrast, this telomere population was $69 \pm 6$ bp shorter than wild type in strains expressing TLC1 with a $\mathrm{Ku}$ site deletion (tlc1 $\Delta 48$; Table 1, second column). Thus, the telomeric repeats are maintained at about one-half the wild-type number in the absence of a Ku site in TLC1.

In the key test, when a Ku site was then added to this binding-defective RNA at either position 446 or 1029 (see Fig. 1), telomeres were longer by a statistically significant amount than those in cells expressing tlc1 $\Delta 48$ (Fig. 3A,B; see also Figs. 4, 5 and Supplemental figures). As summarized in Table 1, based on the results of five independent experiments, $\mathrm{Y}^{\prime}$ telomeres were $20 \pm 5$ bp longer in cells expressing tlc1 $\Delta 48+\mathrm{Ku} @ 446$ than tlc1 $\Delta 48$ (two-tailed $t$-test $P=0.006)$. When the $\mathrm{Ku}$ site was introduced at position 1029 (tlc1 $\Delta 48+\mathrm{Ku} @ 1029)$, data from nine experiments showed that $\mathrm{Y}^{\prime}$ telomeres were lengthened by an average of $22 \pm 7 \mathrm{bp}(P=0.003)$. However, these telomeres were still shorter than wild type (see additional analysis below).

To determine whether there was any telomere length regulation difference with non- $\mathrm{Y}^{\prime}$ telomeres, we took advantage of the $2.1-\mathrm{kb}$ XhoI telomeric restriction fragment (see arrows in Fig. 3A). We found this telomere maps to the right arm of chromosome VI based on analysis of genomic sequence from the Saccharomyces Genome Database (SGD) and Southern blotting with a VI-R-specific subtelomeric probe (Supplemental Fig. 2). The length of this VI-R non$\mathrm{Y}^{\prime}$ telomere was also significantly increased when a $\mathrm{Ku}$ site was reintroduced at position 446 or 1029 in a tlc1 $\Delta 48$ RNA $(P=0.04$ and 0.11 , respectively). The results of relocating $\mathrm{Ku}$ to very different positions in the telomerase RNP demonstrate that alternative Ku-binding sites retain some function in telomerase-mediated telomere length maintenance, although the natural position is more functional than either of the two alternatives tested.

We next tested whether binding of $\mathrm{Ku}$ to the repositioned sites in TLC1 was indeed important for the observed partial restoration of telomere length by introducing a Ku-bindingdefective three-point mutant hairpin $\left(3^{\star} \mathrm{ku}\right)$ (Peterson et al. 2001; Stellwagen et al. 2003) at position 446 or 1029. The constructs with the mutant hairpin were confirmed to be defective in binding $\mathrm{Ku}$, as demonstrated by the Ku-bindingdependent telomeric silencing disruption assay (Supplemental Fig. 3). Furthermore, the $3^{\star}$ ku hairpin did not improve telomere length when introduced at either novel position in tlc1 $\Delta 48$, but rather, the $\mathrm{Y}^{\prime}$ telomeres were $44-65$ bp shorter than those of tlc1 $\Delta 48$ cells (Fig. 3A; Table 1). Using these point-mutant $\mathrm{Ku}$ hairpin RNAs as controls for insertion of functional Ku-binding RNA, the net increase in $\mathrm{Y}^{\prime}$ telomere length caused by $\mathrm{Ku}$ binding to new positions in telomerase is calculated to be 59 and 67 bp for the 446 and 1029 insertions, respectively. This is $91 \%$ of the length by which telomeres shorten when $\mathrm{Ku}$ binding is disrupted $(69 \pm 6 \mathrm{bp}$; see Table 1) and, therefore, in this context targeting $\mathrm{Ku}$ to position 446 or 1029 may provide a nearly wild-type level of telomere-lengthening function.

\section{Ku binding to telomerase RNA increases its abundance}

We analyzed the size and abundance of the TLC1 RNAs with repositioned $\mathrm{Ku}$ sites by Northern blotting. Sizes were as expected considering the various RNA deletions and insertions. Moreover, we discovered that telomerase RNA levels correlated with the number of functional Ku-binding sites in the various TLC1 alleles (Fig. 3C). Strains with the Ku-binding site deleted ( $\operatorname{tlc} 1 \Delta 48)$ showed an average of $0.48 \pm 0.11$ the relative RNA abundance of wild type. Adding a $\mathrm{Ku}$ site to position 446 or 1029 of tlc $1 \Delta 48$ raised the relative level to $0.76 \pm 0.27$ and $0.67 \pm 0.19$, respectively, while adding the $3^{\star} \mathrm{ku}$ binding-defective hairpin caused a relative decrease to 0.20 and 0.22 . In the case of TLC1 alleles where a second $\mathrm{Ku}$ site was introduced at 446 or 1029 , respectively (i.e., in addition to the $\mathrm{Ku}$ site at its

TABLE 1. Relative average length (bp) of telomeres maintained by telomerase RNAs with repositioned Ku sites

\begin{tabular}{|c|c|c|c|c|c|c|c|c|c|c|c|}
\hline \multirow[b]{2}{*}{ TLC1 allele: } & \multirow[b]{2}{*}{ TLC1 } & \multirow[b]{2}{*}{ tlc1s } & \multicolumn{5}{|c|}{ tlc1 $1 \Delta 48$} & \multicolumn{4}{|c|}{ TLC1 } \\
\hline & & & & +Ku@446 & +Ku@1029 & +3*Ku@446 & +3*Ku@1029 & +Ku@446 & +Ku@1029 & +3*Ku@446 & +3*Ku@1029 \\
\hline $\begin{array}{l}\text { Y'-proximal } \\
\text { telomeres: }\end{array}$ & $\mathbf{0}$ & $-\mathbf{1 3 9} \pm 12$ & $-69 \pm 6$ & $-49 \pm 7$ & $-47 \pm 7$ & -108 & -114 & $+36 \pm 12$ & $+\mathbf{1 2} \pm 5$ & $-\mathbf{4 4} \pm 11$ & $-65 \pm 11$ \\
\hline $\begin{array}{l}\text { VI-R } \\
\text { telomere: }\end{array}$ & $\mathbf{0}$ & $-198 \pm 22$ & $-\mathbf{1 1 6} \pm 6$ & $-\mathbf{8 9} \pm 12$ & $-\mathbf{5 8} \pm 27$ & $-20^{a}$ & -190 & $+\mathbf{4} \pm 52$ & $+\mathbf{4 0} \pm 45$ & -93 & $\mathbf{- 1 0 2} \pm 19$ \\
\hline
\end{tabular}



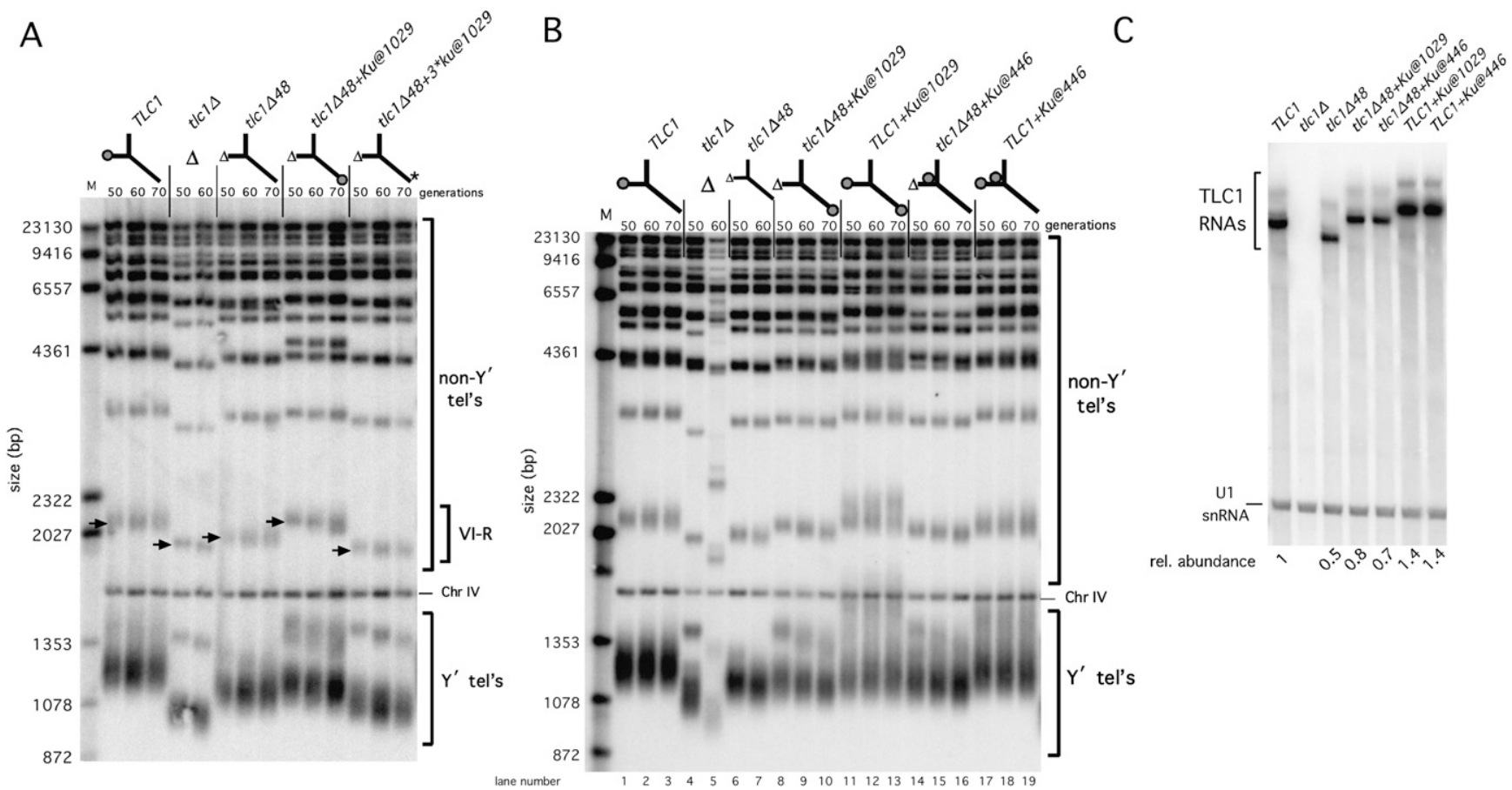

FIGURE 3. Reintroduction of a functional Ku site at a new position in tlc1 148 RNA partially restores telomere length and RNA abundance. (A) A functional $\mathrm{Ku}$ site, but not a mutated one $\left(3^{*} \mathrm{ku}\right)$, improves telomere length when introduced at the tip of the terminal arm (after nucleotide 1029) of a TLC1 RNA missing the endogenous 48-nt Ku-binding hairpin. Southern blot of XhoI-digested genomic DNA from yeast cultures grown for 50 to 70 generations and probed for telomere repeat DNA sequence. The TLC1 RNA and relationship to Ku binding is schematized above the blot. (Chr IV) Nontelomeric XhoI restriction fragment control for loading and relative mobility on the gel. ( $\mathrm{Y}^{\prime}$ tel's) The $17 \mathrm{XhoI}$ restriction fragments from chromosome ends with a subtelomeric $\mathrm{Y}^{\prime}$ element, which has an XhoI site. (Non- $\mathrm{Y}^{\prime}$ tel's) Restriction fragments from the remaining 15 chromosome ends. The $2.1-\mathrm{kb}$ telomeric restriction fragment indicated by an arrow for each set of TLC1 alleles comprises the right end of chromosome VI (see Supplemental Fig. 2). (B) A functional Ku site at position 446 or 1029 increases telomere length of tlc1 $\Delta 48$ and also TLC1 RNAs. Southern blot was performed as in $A$. (C) Telomerase RNA abundance decreases by half when the Ku-binding site is deleted and increases with addition of a binding site at a new position. Northern blot of total RNA isolated from log-phase yeast cells and hybridized with probes for TLC1 and the 569-nt U1 snRNA SNR19 (Kretzner et al. 1987). Northern blot signal intensity for U1 is lower than TLC1 because 1\% of the amount of radioactive probe DNA was used for U1 compared with TLC1. U1 levels were used to normalize TLC1 abundance and calculate relative level of TLC1 RNA, shown below the gel.

normal position), the relative RNA abundance was increased to $1.29 \pm 0.52$ and $1.21 \pm 0.42$, while it was reduced by a $3^{\star} \mathrm{ku}$ hairpin to 0.68 and 0.43 .

We also tested the TLC1 alleles with repositioned $\mathrm{Ku}$ sites when integrated in the chromosome rather than expressed from CEN plasmids. Analysis of telomere length showed the same modest, but statistically significant contribution of the repositioned sites (Supplemental Fig. 4), despite a decrease of $\sim 40 \%$ in RNA abundance due to differences in copy number between CEN plasmids and chromosomes. Furthermore, the integrated alleles were in a wild-type RAD52 background, whereas the strain used with CEN plasmids is a rad52 $\Delta$ mutant, so this also demonstrates that the results are RAD52 independent.

\section{Two Ku sites in TLC1 causes progressive telomere hyperlengthening}

Southern blotting analysis suggested that telomeres were reproducibly longer than wild type for TLC1 alleles that retained the endogenous $\mathrm{Ku}$ site and also had another one introduced at 446 or 1029 (Fig. 3B, lanes 11-13,17-19). We addressed this in more detail by performing an extended time course of cell growth through 300 generations (Fig. $4 \mathrm{~A}$ ). We observed progressive hyperelongation of the chromosome VI-R telomere by 255 bp (Fig. 4A, lanes 22-25) over this 225-generation time period; or $\sim 1$ bp per generation on average. Similar gradual hyperlengthening was observed for a subset of the $\mathrm{Y}^{\prime}$ telomeres and other non- $\mathrm{Y}^{\prime}$ telomeres; it appeared to occur stochastically with respect to the particular chromosome end that was affected (e.g., chromosome end VI-R was not always hyperelongated). This progressive hyperlengthening of telomeres was never observed when the binding-defective $3^{*} \mathrm{ku}$ sequence was introduced into TLC1 at 446 or 1029.

\section{RNA abundance is not the cause of telomere length phenotypes of TLC1/Ku alleles}

Telomere length in diploid yeast cells is sensitive to TLC1 copy number, probably because there are normally extremely low levels of the RNA, approximately stoichiometric 
A

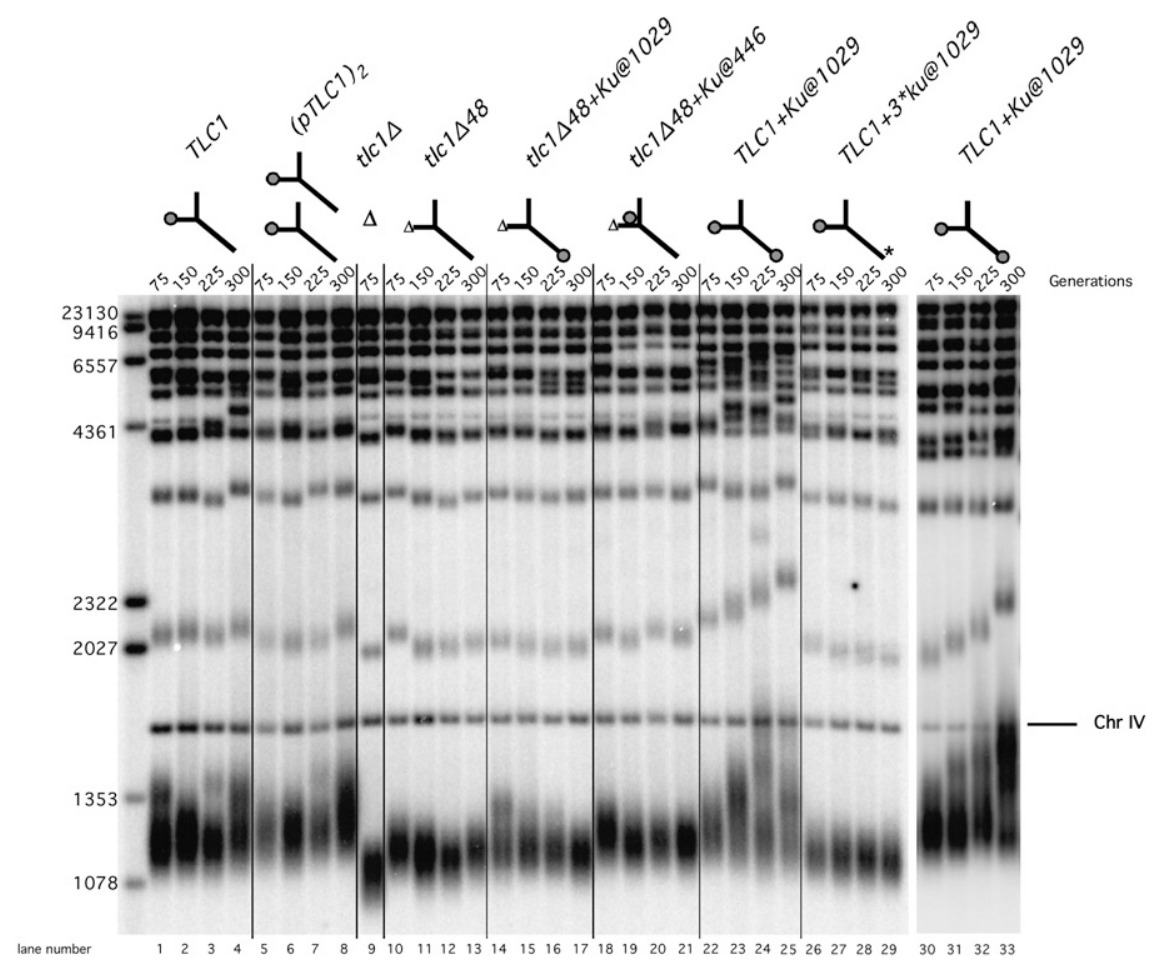

B

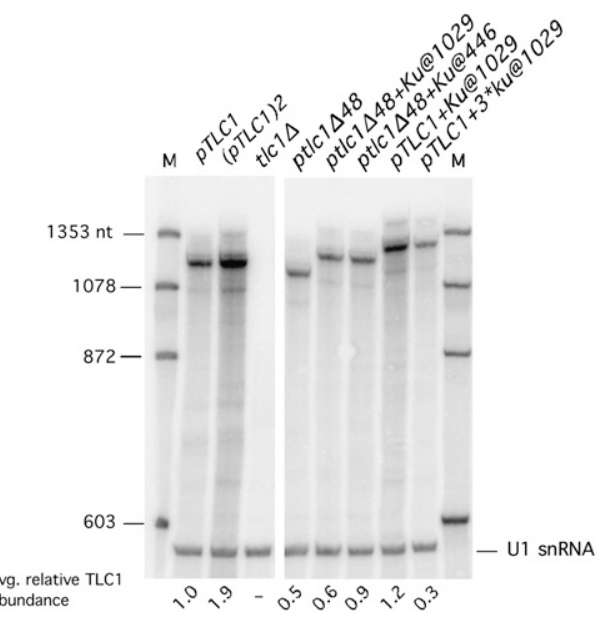

C

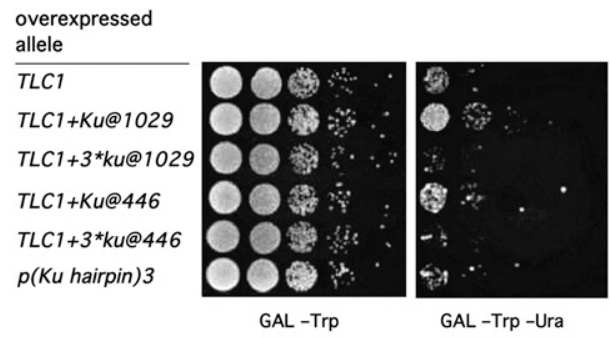

FIGURE 4. Telomere hyperlengthening is caused by TLC1 RNA containing two Ku sites. (A) Expression of TLC1 with two functional Ku sites leads to gradual runaway lengthening of a variable subset of telomeres. Note the greater generation number than in Figure 3. $(B)$ Doubling the number of centromeric plasmids per cell expressing wild-type TLC1 provides a twofold increase in TLC1 RNA, just slightly more than TLC1 alleles with two Ku sites expressed from a single CEN plasmid. Northern blotting was performed as in Figure 3C. (C) TLC1 RNAs with two Ku sites cause greater disruption of telomeric silencing than wild type. [ $\mathrm{p}(\mathrm{Ku} \text { hairpin })_{3}$ ] Positive control construct with three Ku sites, which causes potent disruption of TPE. Experiment was performed as in Figure 2B.

to telomeres (Mozdy and Cech 2006). Telomerase RNA haploinsufficiency is also associated with dyskeratosis congenita in humans (Wong and Collins 2006). We have shown here that when the Ku-binding site in TLC1 is deleted, RNA abundance decreases to $48 \pm 11 \%$. To test the possibility that this might completely explain shorter telomeres in tlc1 $\Delta 48$ cells, we increased tlc1 $\Delta 48$ RNA abundance twofold by transforming $t l c 1 \Delta$ cells with two different tlc1 $\Delta 48$ expressing CEN plasmids, each with a different selectable marker. Maintaining selection for both plasmids led to a cellular increase in tlc1 148 RNA to $98 \%$ of wild-type RNA levels, but only a 14-bp increase in average $\mathrm{Y}^{\prime}$ telomere length, still $28 \mathrm{bp}$ shorter than the wild-type telomeres in the experiment (all experimental groups were done in duplicate from 50 to 300 generations; see Supplemental Fig. 6). Thus, even with almost exactly the wild-type amount of tlc1 $\Delta 48$ RNA in vivo, telomeres are short, supporting a direct role for the $\mathrm{Ku}$ telomerase subunit in telomere lengthening. 

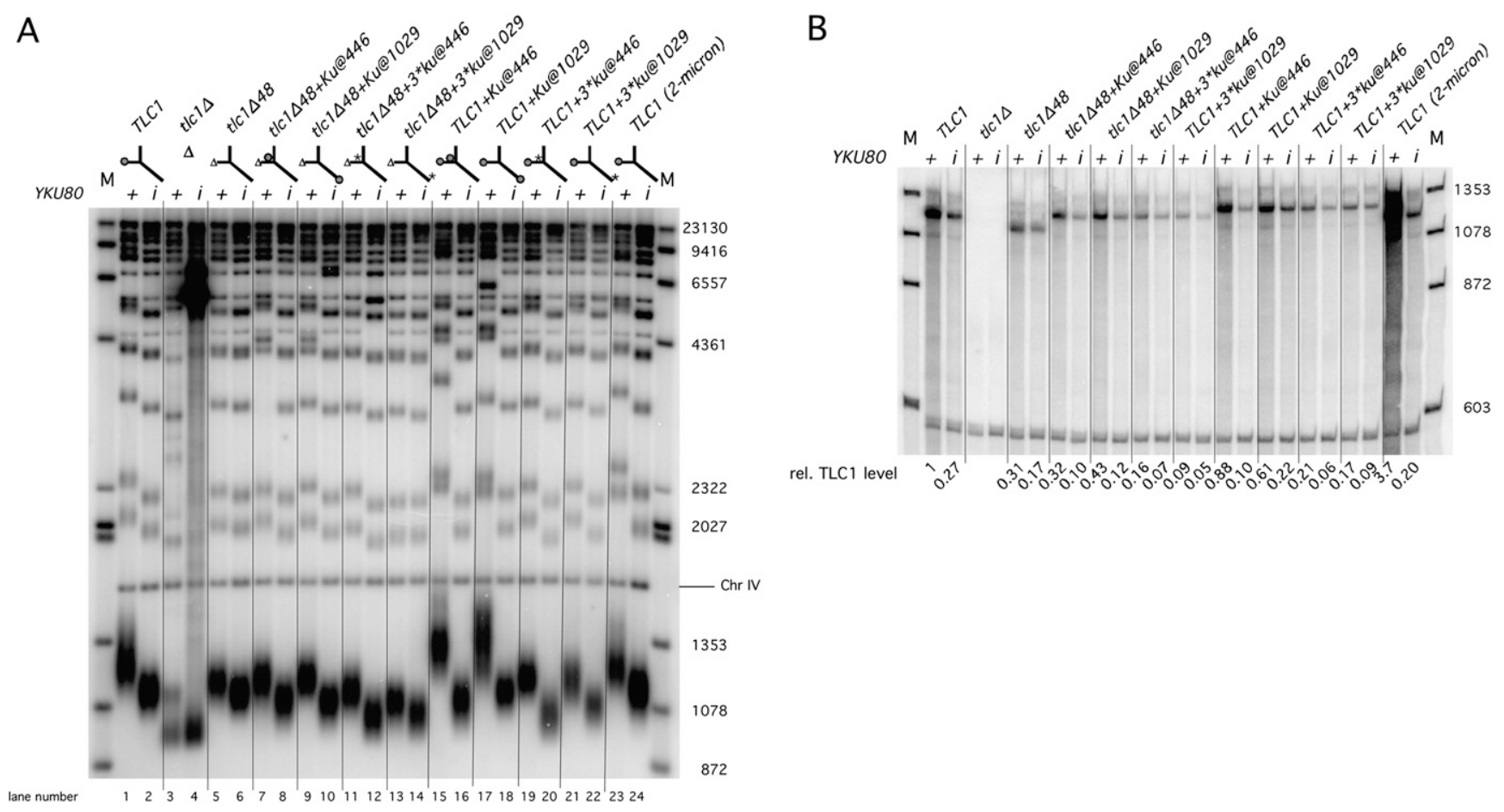

FIGURE 5. A five-amino acid insertion in Yku80p (yku80-135i) that disrupts TLC1 binding leads to a significant decrease in telomere length for TLC1 alleles with functional Ku sites and a decrease in RNA abundance. (A) Telomeric Southern blot for various TLC1 alleles in a YKU80 (+) or $y k u 80-135 i$ (i) strain background. (B) Northern blot from logarithmically growing cells probed for TLC1 RNAs and U1 snRNA. Relative levels of TLC1 RNA (normalized to U1 snRNA) are shown below.

TLC1 RNA with an additional $\mathrm{Ku}$ site was, on average, $25 \pm 7 \%$ more abundant (Fig. 4B; data not shown; see also Figs. 3C, 5B; Supplemental Figs. 6, 7), also consistent with $\mathrm{Ku}$ contributing to telomerase RNA levels. TLC1 alleles with two Ku-binding sites indeed bind more Ku protein, as shown in Figure 4C; galactose-inducible RNA overexpression causes at least twofold more telomeric silencing disruption than wild-type TLC1. Since the TLC1+Ku@446 and @1029 alleles also have telomeres longer than wild type, we tested whether this might simply be due to increased telomerase RNA levels. The level of wild-type TLC1 was increased to that of $\mathrm{TLC} 1+\mathrm{Ku}$ RNAs using the two-CEN-plasmid approach as described above to double gene copy number. Indeed, growing these cotransformants in doubly selective medium led to approximately twice the TLC1 RNA abundance per cell (Fig. 4B), yet the length of telomeres was indistinguishable from that of yeast harboring wildtype TLC1 on a single CEN plasmid (Fig. 4A, lanes 5-8). Thus, doubling the normal concentration of TLC1 RNA in vivo did not lead to a discernable telomere length hyperelongation phenotype in the otherwise isogenic haploid strain. Therefore, hyperlengthening of telomeres caused by TLC1 with an extra $\mathrm{Ku}$ site is probably due to increased function of $\mathrm{Ku}$ in promoting telomerase activity, and not simply an indirect effect of $\mathrm{Ku}$ stabilizing telomerase RNA.

\section{A telomerase RNA-binding defective allele of Ku80 shows that normal telomere length and TLC1 RNA levels require the $\mathrm{Ku}-\mathrm{TLC} 1$ interaction}

In the above experiments, we manipulated $\mathrm{Ku}$ binding to telomerase RNA by mutating and repositioning $\mathrm{Ku}$ sites in the RNA. To determine whether these effects were due to changes in $\mathrm{Ku}$ binding or changes in the RNA structure, we next disrupted the Ku-TLC1 interaction by introducing a mutation in YKU80, the gene encoding the Ku subunit responsible for binding telomerase RNA (Stellwagen et al. 2003). We replaced the chromosomal copy of YKU80 with yku80-135i, a 15-nt insertion mutant identified by screening a transposon-mutagenized library of $\mathrm{Ku}$ alleles for those specifically defective in binding TLC1 (Stellwagen et al. 2003). We then transformed the YKU80 and $y k u 80-135 i$ versions of this $t l c 1 \Delta$ strain with the various centromeric plasmid-borne TLC1 alleles with altered $\mathrm{Ku}$ sites and assessed the telomere length and RNA abundance in these clones after 300 generations.

As seen previously (Stellwagen et al. 2003), with wildtype TLC1 telomere length was shorter in the $y k u 80-135 i$ strain than in the YKU80 strain (Fig. 5A, lanes 1,2). Average $\mathrm{Y}^{\prime}$ telomere length in the TLC1 $y k u 80-135 i$ strain was 113 bp shorter than wild type, similar to the 95-bp decrease in the tlc1 488 YKU80 strain (cf. lanes 2,5). Telomere length 
was more significantly affected by the $y k u 80-135 i$ mutation in cases where a functional $\mathrm{Ku}$ site was present in the TLC1 RNA-be it only at the endogenous location ( $-113 \mathrm{bp})$, only an unnatural one $(-72 \mathrm{bp})$, or at both positions ( $-182 \mathrm{bp}$ ) - than for the defective tlc1 $\Delta 48$ allele ( $-36 \mathrm{bp}$ ) or cases where a $3^{\star} \mathrm{ku}$ hairpin was introduced into $t \mathrm{cl} 1 \Delta 48$ $(-49 \mathrm{bp})$ (Fig. 5A). These results provide additional evidence that $\mathrm{Ku}$ binding to TLC1 is responsible for the observed telomere length phenotypes.

Consistent with the decrease in TLC1 RNA abundance we observed in tlc1 448 YKU80 cells, TLC1 $y k u 80-135 i$ cells have $\sim 30 \%$ the TLC1 abundance of TLC1 YKU80 cells (Fig. 5B). Interestingly, there was a discernable effect of the $y k u 80-135 i$ mutation even without a functional $\mathrm{Ku}$ site in the TLC1 RNA, but it was generally smaller than for those TLC1 alleles with a Ku-binding site.

\section{TLC1 alleles with repositioned Ku-binding sites still promote telomere healing at broken DNA ends}

$\mathrm{Ku}$ is one of several telomere-binding proteins that interact with telomerase to promote telomere addition at native chromosome ends. However, $\mathrm{Ku}$ also interacts with telomerase to promote telomere addition at broken DNA ends, particularly when DNA damage is accompanied by substantial deletions within a chromosome (Stellwagen et al. 2003; Pennaneach et al. 2006). To explore whether TLC1 alleles with repositioned $\mathrm{Ku}$-binding sites remain able to promote telomere healing at broken chromosome ends, we used the gross chromosomal rearrangements (GCR) assay developed by Kolodner and colleagues. In this assay, two counter-selectable markers, URA3 and CAN1, are located $\sim 10 \mathrm{~kb}$ apart on the left arm of chromosome $\mathrm{V}$ and distal to the most telomere-proximal essential gene, PCM1 (Fig. 6A). Spontaneous or induced DNA damage can cause the loss of chromosomal DNA containing both URA3 and CAN1 while retaining $P C M 1$; the vast majority of these DNA damage events are healed by the addition of a telomere to the centromere-proximal DNA end (Myung et al. 2001).

GCR assays were performed using strains with the genomic copy of TLC1 replaced with $t l c 1 \Delta 48, t l c 1 \Delta 48+K u @ 446$, or tlc1 $\Delta 48+K u @ 1029$. Native telomeres in these strains were maintained at lengths similar to those in strains with these tlc1 alleles on CEN plasmids (Supplemental Fig. 4). DNA damage was induced using the alkylating agent methyl methanesulfonate (MMS), and GCR events were identified by plating on media containing 5-fluoroorotic acid (FOA) and canavanine. Under these conditions, the $t l c 1 \Delta 48$ strain exhibited a 10-fold lower GCR frequency than the wildtype strain (Fig. 6B). However, GCR frequencies in strains

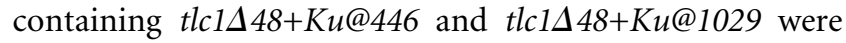
three- to fivefold increased over the $\operatorname{tlc} 1 \Delta 48$ strain. These increases were seen under a range of MMS concentration conditions, and Southern blot analysis verified that the majority of GCR events were the result of new telomere
A

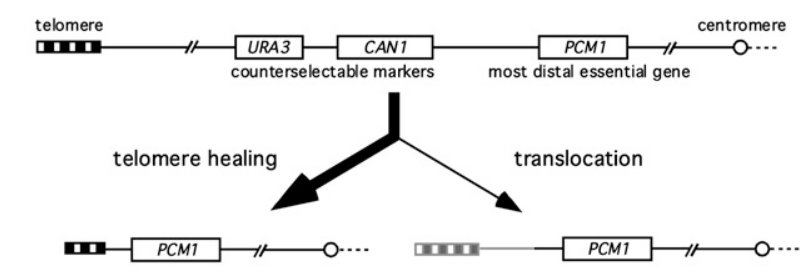

B

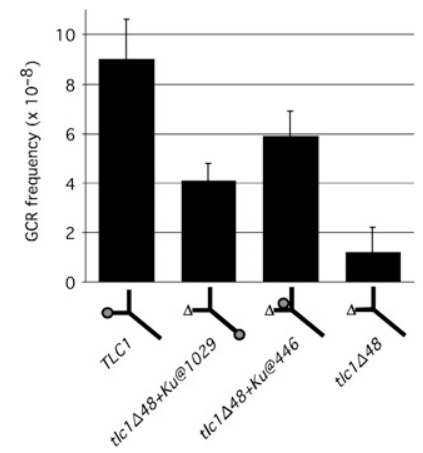

FIGURE 6. TLC1 alleles with repositioned Ku-binding sites support telomere healing at broken DNA ends. (A) Schematic of chromosome V-L. The URA3 and CAN1 genes are $\sim 10 \mathrm{~kb}$ apart and distal to PCM1, the last essential gene on this chromosome arm. Most DNA damage that causes the loss of both URA3 and CAN1 is healed by the addition of a telomere (black and white boxes); a minority is healed by chromosomal translocation (gray line). (B) GCR frequencies of strains containing the indicated TLC1 alleles, determined by counting colonies of surviving cells after inducing DNA damage.

addition (data not shown). These results suggest that the TLC1 RNAs with repositioned Ku-binding sites retain approximately half the ability to promote telomere healing at broken DNA ends.

\section{De novo telomere addition is reduced when the Ku-binding site is repositioned in TLC1}

To investigate whether telomerase-mediated extension of a broken chromosome end is affected when the $\mathrm{Ku}$ site is repositioned in TLC1, we measured the rate of telomere addition at a defined site on chromosome VII using an assay developed by Diede and Gottschling (1999) (Fig. 7A).

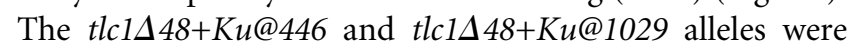
integrated into a strain in which a short telomeric seed sequence is located next to a recognition site for the $\mathrm{HO}$ endonuclease. Induction of $\mathrm{HO}$ exposed the telomeric seed, and the rate of new telomeric sequence addition to the seed was monitored over time by Southern analysis (Fig. 7B).

In all strains, cleavage of the $\mathrm{HO}$ site was largely complete after the first hour of the endonuclease's induction (note disappearance of uncut band and appearance of cut band in Fig. 7B). In the wild-type strain, telomere addition was detectable after $2 \mathrm{~h}$, as indicated by the smear of signal above the cut band; by $4 \mathrm{~h}$, more than half of the cut fragments had 


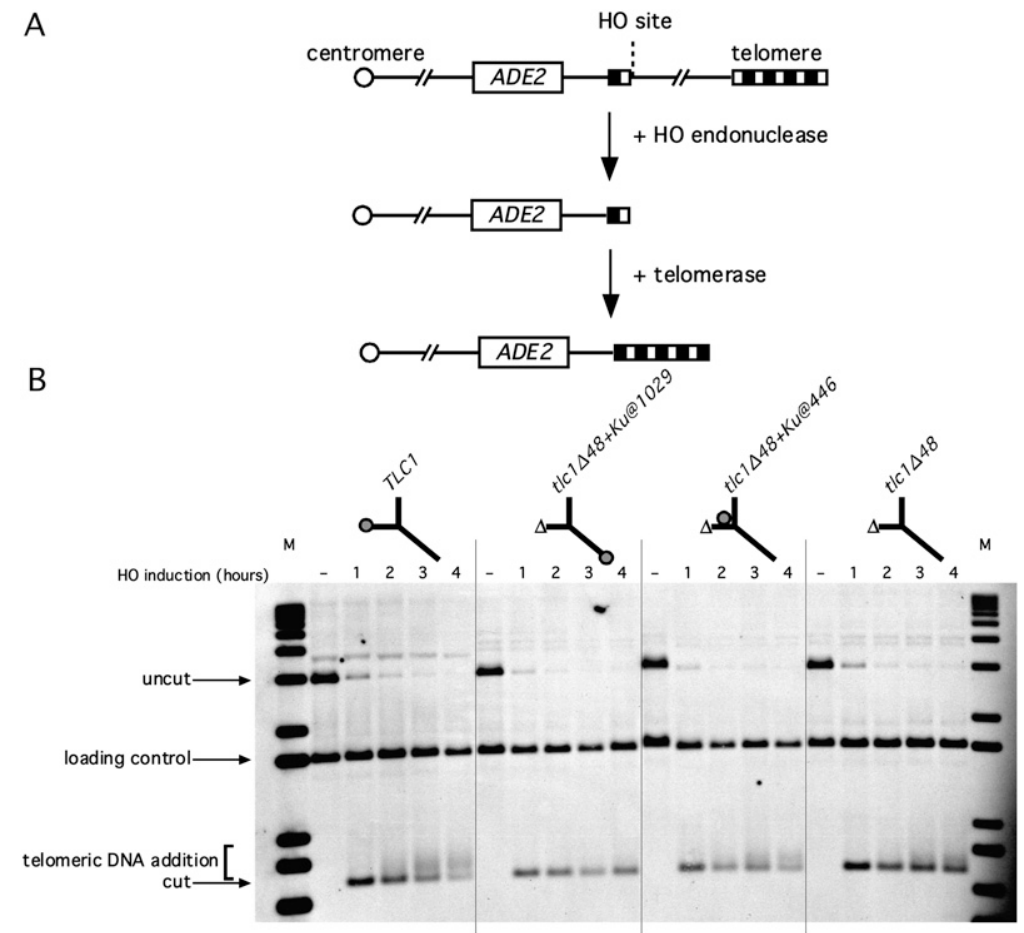

FIGURE 7. Reduced de novo telomere addition in strains with repositioned Ku-binding sites in TLC1 RNA. (A) The de novo telomere addition experiment. An 81-bp telomeric seed sequence (single pair of internal black and white boxes) is located next to an $\mathrm{HO}$ endonuclease recognition site. Induction of $\mathrm{HO}$ and subsequent chromosomal DNA cleavage exposes this telomeric seed, which is then elongated by telomerase. (B) Southern analysis of de novo telomere addition. Genomic DNA was collected at the indicated times after HO induction, digested with SpeI, and analyzed by Southern blot hybridization to an ADE2 probe. This probe also binds to a $\sim 1.6-\mathrm{kb}$ fragment from the native $A D E 2$ locus, which serves as a loading control.

been elongated. These kinetics were slower in the $\operatorname{tlc} 1 \Delta 48$ strain: The smear of elongation was detected later, and a smaller fraction of the cut fragments were elongated. Neither

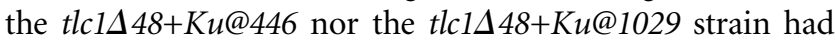
telomere addition restored to wild-type levels. In the latter case, little telomere addition was detectable within the first 4 $\mathrm{h}$; longer time courses revealed that telomere healing was underway after $8 \mathrm{~h}$, and these strains did not exhibit any loss of viability when plated, in contrast to telomerase-deficient strains (data not shown).

\section{DISCUSSION}

In this study, we tested whether scaffolding of the $\mathrm{Ku}$ subunit by TLC1 RNA is flexible, in the sense that it can function in different positions in the telomerase RNP. We deleted the endogenous binding site in TLC1 and then added it back at two new positions, hundreds of nucleotides away from the normal location. The hypothesis, based on the flexible scaffolding model already demonstrated for the essential Est1 subunit (Zappulla and Cech 2004) was that $\mathrm{Ku}$ would provide its function in telomerase despite being relocated within the enzyme complex. As described in detail below, repositioning of $\mathrm{Ku}$ allows some retention of its functions, but does not exhibit the degree of positional flexibility exhibited by the Est1 subunit.

We first tested whether $\mathrm{Ku}$ would bind to the repositioned hairpins in vivo. This was determined by the ability of TLC1 to bind to $\mathrm{Ku}$ and disrupt Ku's essential role in the telomere position effect. Indeed, $\mathrm{Ku}$ bound to repositioned sites in TLC1, causing disruption of telomeric silencing indistinguishable from the wild-type RNA. This result demonstrates flexibility in the ability of $\mathrm{Ku}$ to associate with the telomerase RNP, a prerequisite for testing for flexibility of its function at these novel positions.

We report here that deletion of the 48-nt Ku-binding site leads to a decrease in TLC1 RNA abundance in vivo to $48 \%$ of wild type. The binding of $\mathrm{Ku}$ to repositioned hairpins in the TLC1 leads to substantial recovery of the RNA to nearly the wild-type level. Furthermore, TLC1 alleles with a functional $\mathrm{Ku}$ site have significantly decreased abundance when the binding-defective yku80-135p is introduced. Consistent with our results, a relative TLC1 abundance of 53\% has been reported for a $y k u 70 \Delta$ mutant (Mozdy et al. 2008). Given that Yku70 forms a heterodimer with Yku80p, this would presumably disrupt $\mathrm{Ku}$ function in telomerase to an extent similar to that described here. Ku could promote telomerase RNA abundance by stabilizing the RNP and/or by enhancing its nuclear retention (Gallardo et al. 2008). Although we have not explored the detailed mechanism, we show here that the increase in TLC1 abundance requires $\mathrm{Ku}$ binding to the RNA and is flexible with respect to Ku's position in the RNP.

Telomere length is maintained when the $\mathrm{Ku}$ site is repositioned in TLC1. Ku at the repositioned sites may be functioning at near wild-type efficiency when one factors in that a three-point mutation $\left(3^{\star} \mathrm{ku}\right)$ version of the $\mathrm{Ku}$ hairpin that is defective in binding $\mathrm{Ku}$ actually shortens telomeres when put at the same positions. This is consistent with Ku's function in telomerase-mediated telomere length maintenance being mostly retained despite $\mathrm{Ku}$ binding to completely new positions in the RNP. We also assessed the ability of repositioned $\mathrm{Ku}$ in telomerase to enable cells to survive with gross chromosomal rearrangements (GCRs) via addition of telomeric DNA to internal positions of a damaged chromosome. In this case, repositioned $\mathrm{Ku}$ sites had an intermediate ability to facilitate telomerase-mediated GCRs. 
Why do the TLC1 alleles with repositioned $\mathrm{Ku}$ sites function intermediately well in telomere length maintenance and in the gross chromosomal rearrangements assay? We propose that one contribution to these intermediate phenotypes and to the somewhat reduced levels of RNA accumulation is a $\mathrm{Ku}$-independent partial loss-of-function associated with introducing hairpin sequence at either position 446 or 1029 , which is supported by phenotypes of the $3^{*} \mathrm{ku}$ site introduced at either location. This was unexpected, since integrating Estlp-binding sites previously (Zappulla and Cech 2004) did not cause this partial loss of TLC1 function or abundance of telomerase, and since RNA folding simulations using Mfold did not predict additional changes in secondary structure beyond those designed.

Furthermore, results from the de novo broken endhealing assay demonstrate that TLC1 alleles with repositioned $\mathrm{Ku}$ sites are slow during the initial hours to add telomeric DNA to an introduced chromosome break. This result demonstrates that the kinetics of telomere addition is reduced when the $\mathrm{Ku}$ site is repositioned in the RNP. Slow kinetics of telomerase action when TLC1 has its Ku hairpin repositioned may also be responsible for the intermediate telomere length and degree of gross chromosomal rearrangements. There are alternative DNA repair mechanisms that can lead to GCRs (Pennaneach et al. 2006), and these may outcompete a less efficient telomerase. The decreased rate of telomere addition in the cases of telomerase with repositioned $\mathrm{Ku}$ may occur at the stage of telomerase recruitment to the broken DNA end or could also be caused by a decrease in the rate or processivity of telomerase elongation.

TLC1 alleles that retain the endogenous $\mathrm{Ku}$ site and also have an additional one at 446 or 1029 (see Fig. 1) lead to dysregulation of telomere length maintenance; hyperelongation of telomeres steadily continues over the course of a month of restreaking yeast colonies on solid medium (300 generations). There is also slightly increased TLC1+Ku RNA accumulation, but the increased amount of RNA, per se, is not the cause of the runaway telomeres, because doubling the level of wild-type TLC1 does not cause such an effect. Furthermore, the telomere lengthening is dependent on Ku protein being competent to bind RNA, based on our experiments using the $y k u 80-135 i$ allele. Additionally, we have shown that a triple point mutant $\mathrm{Ku}$ site hairpin, when added to wild-type TLC1 at either position, actually leads to telomere shortening, not lengthening. Thus, we conclude that it is the binding of additional Ku protein to TLC1 RNA that leads to progressive telomere hyperlengthening. The relatively high concentration of $\mathrm{Ku}$ in the nucleus is consistent with the model that $\mathrm{TLC} 1+\mathrm{Ku}$ alleles bind more $\mathrm{Ku}$ per RNA molecule than wild type. In fact, assessment of binding using disruption of telomeric silencing (DOT) assays (Singer and Gottschling 1994) further support this, as GAL-overproduced TLC1+Ku RNAs disrupt telomeric si- lencing more efficiently than wild-type TLC1 (Fig. 4C). Thus, if an additional $\mathrm{Ku}$ site in TLC1 leads to loading of up to two $\mathrm{Ku}$ heterodimers per telomerase (or alternatively doubles the chance that each telomerase RNP has at least one Ku70-80 heterodimer), then this may increase the rate of telomerase recruitment to telomeres. This could then lead to longer telomeres. However, it is also conceivable that $\mathrm{Ku}$ plays a role in telomerase processivity, as has been found recently for POT1-TPP1 and human telomerase (Wang et al. 2007); in this case, the increased number of Ku sites in TLC1 would lead to more extensive telomere addition at a stage after telomerase recruitment.

The observation that the two-Ku-site TLC1 RNAs support hyperextension of only a fraction of $\mathrm{Y}^{\prime}$ telomeres, and some of the non- $Y^{\prime}$ telomeres more than others, is intriguing. Different non- $Y^{\prime}$ telomeres were preferentially extended in independent experiments. Thus, it appears that telomere and/or telomerase composition or their nuclear location may determine which telomeres are hyperextended, rather than some difference in subtelomeric DNA sequence.

Because $\mathrm{TLC} 1+\mathrm{Ku}$ alleles cause an increase in telomere length regulation via the $\mathrm{Ku}$ pathway for telomerase recruitment to the telomere, we thought it could be possible that two $\mathrm{Ku}$ sites per RNA could potentially suppress the senescence phenotype of a tlc1 mutant deleted for the Estlpbinding site (tlc1 $\Delta$ bulge) (Seto et al. 2002). Thus, we cloned tlc1 $\Delta$ bulge+Ku@1029 and tlc1 $\Delta$ bulge+Ku@446 CEN plasmids and tested these for function in vivo in a $t l c 1 \Delta$ strain. Independently isolated transformants of each construct expressed RNAs of the expected size, and RNA abundance was $80 \%$ of wild type (Supplemental Fig. 7), but these cells still senesced due to ever-shortening telomeres. These results demonstrate that the gain-of-function provided by the two $\mathrm{Ku}$ sites was insufficient to overcome the absence of binding the essential Estlp subunit and support a model with functionally distinct roles for these telomerase subunits.

Our data suggest that telomerase with repositioned $\mathrm{Ku}$ sites performs better when extending native telomeres than broken chromosome ends. We propose that the reason for this may relate to the difference between these chromosome end substrates. At native telomeres, there are two wellcharacterized telomerase recruitment pathways, probably acting in parallel: the essential one is mediated by the telomeric DNA-binding protein Cdc13p and its TLC1binding partner Estlp, while the other is mediated by the DNA- and TLC1-binding Ku heterodimer. At broken chromosome ends, it has been proposed that both of these pathways can facilitate telomerase recruitment (Myung et al. 2001; Bianchi et al. 2004; Fisher and Zakian 2005). However, one might expect that the role of the DNA endbinding $\mathrm{Ku}$ heterodimer is predominant, with the Cdc13Est1 pathway probably being only responsible for recruiting telomerase when a significantly long and GT-rich ssDNA Cdc13p-binding consensus $\left(\mathrm{GxGTx}_{7}\right)$ (Eldridge et al. 2006) is revealed by some processing at the break (Zhang and 
Durocher 2010). Thus, at broken chromosome ends, it seems likely that $\mathrm{Ku}$ may often function independently of the Cdc13-Est1 pathway in telomerase recruitment, since it can bind quickly and may then protect the end from being resected by nucleases and it can then either facilitate nonhomologous end-joining or recruit telomerase. We envision that broken end-bound $\mathrm{Ku}$ may have to coordinate telomerase activity on the end with some structural orientation requirements that do not exist at a native telomere, which has a 3' overhang bound to Cdc13p and where other telomerebinding proteins are also present. Thus, with respect to the broken chromosome end as a substrate, there may be less flexibility tolerated in the telomerase RNP than at native telomeres.

\section{MATERIALS AND METHODS}

\section{RNA-folding predictions}

To aid our design of telomerase RNA alleles with repositioned $\mathrm{Ku}-$ binding sites, we utilized Mfold (v. 3.2) RNA folding software, which has previously been shown to provide useful predictions for folding of telomerase RNA from Saccharomyces species. To help preserve the correct folding of the 48-nt Ku-binding site when moved to new positions within TLC1 RNA, we inserted a 74-bp portion of the TLC1 gene at these positions (at the unique NcoI and BclI sites in TLC1), which includes additional paired nucleotides at the base of the 48-nt Ku-binding hairpin (see Results). The Mfold predictions for telomerase RNA are shown in Supplemental Figure 1.

\section{Plasmids}

The tlc1 $\Delta 48$ allele is encoded on yeast shuttle plasmid pDZ154, which was made by cutting pSD107 (TLC1 from BglII-PstI cloned into pRS314) with BsrGI and NcoI to insert a PCR fragment amplified from pRS306-tlc1 $\Delta 48$ (Peterson et al. 2001). pKG210 is pDZ154 digested with BclI (position 1029) to insert a PCR product with 74-nt $\mathrm{Ku}$ hairpin sequence (from AATTTGTGG through CGTAAATT; position 262 through 335) amplified from pSD107. (Note that nucleotide position 1029, for example, is the same as 1033 described previously [Zappulla and Cech 2004]; it has been updated to reflect the new $5^{\prime}$ end [Dandjinou et al. 2004] as well as listing the insertion position as the nucleotide after the 3 '-most nucleotide end of each restriction enzyme recognition site in TLC1.) Plasmid pKG212 is like pKG210 described above, except with the $\mathrm{Ku}$ site inserted at the NcoI site (position 446) instead of at the BclI site. pKG211 and pKG213 are like pKG210 and pKG212, respectively, except that the starting plasmid used for the cloning was pSD107 (with wild-type TLC1) instead of pDZ154 (tlc1 $\Delta 48)$. The tlc1 $\Delta 48+\left(\right.$ inverted- $\left.\mathrm{Ku}_{2}\right) @ 1029$ is harbored on pKG214 and was cloned by inserting two 74-nt Ku sites at BclI site into pDZ154, with the first insert being in the forward direction and the second backward. This clone was identified by digestion with enzymes flanking the BclI site, which liberated a fragment that demonstrated two inserts, and by sequencing (which, from both directions, only went about 9 nt into the inverted Ku site hairpin). The TLC1+3*ku@1029 allele is present on plasmid pKG220 and was cloned like pKG211, except that the 74-nt hairpin PCR fragment inserted had the three point mutations previously reported (Peterson et al. 2001). The triple point mutation (U291A, U297G, U314G) insert was generated by PCR using two oligos, one of which was very long and had the three desired mutations within it (details of oligos are available upon request). The following plasmids correspond to pKG211, pKG212, and pKG213, respectively, except that each has a triple mutant hairpin instead of the wild-type one: pKG220, pKG228, and pKG222.

The high-copy TLC1 plasmid pKG237 that was used in Figure 5B contains TLC1 cloned from the BamHI-PstI site, before and after the gene, into pRS424 ( $2 \mu$, TRP1). The overexpression plasmids $\mathrm{pTLC} 1^{\S}$ and $\mathrm{p}(\mathrm{Ku} \text { hairpin })_{3}$ used in Figure 2 have been previously described as pTCG61 and pTCG-3X stem (Peterson et al. 2001). Galactose overexpression plasmids for TLC1, tlc1 $\Delta 48+\mathrm{Ku} @ 1029$, tlc1 $\Delta 48+\mathrm{Ku} @ 446$, and tlc1 $\Delta 48$ were created by replacing the BamHI-StuI fragment of $\mathrm{pTLC1}^{\S}$ with a blunted StuI-NdeI fragment from pSD107, pKG210, or pKG212. The popin/pop-out plasmids pJA002 and pJA004 were made by replacing the NotI-XhoI fragment of pRS306 + TLC1 (Peterson et al. 2001) with a NotI-XhoI fragment from pKG210 or pKG212.

\section{Yeast strains}

Strain TCy43 (MATa ura3-52 lys2-801 ade2-101 trp1- $\Delta 1$ his3- $\Delta 200$ leu2- $\Delta 1$ VR::ADE2-TEL adh4::URA3-TEL tlc1::LEU2 rad52:: LEU2 [pTLC1/LYS2/CEN]) was used for testing functionality of TLC1 alleles as shown in Figures 3-5. Strain UCC6078-1 and a yku80-135i derivative, MSy24, were used for the experiments shown in Figure 5A,B. MSy24 was constructed by cutting plasmid pRS305-yku80-135 with SwaI and transforming UCC6078-1 and plating on -Ura and then popping out the wild-type YKU80 allele by selection on SC + 5-FOA medium. Correct pop-out was screened for by yeast colony PCR using a variety of mutantand wild-type-specific primers. The wild-type TLC1 plasmid in strain UCC6078-1 marked with LYS2 was shuffled out by spontaneous loss and replaced with plasmid pTLC1(URA3) (a gift from Amy J. Davis, University of Utah). Plasmid-shuffle was then performed using 5-FOA to counterselect this plasmid after transformation with mutant TLC1 alleles on pRS314-based plasmids with a TRP1 selectable marker.

Strain UCC3505 (Singer and Gottschling 1994) was used for telomeric silencing assays, while UCC5913 (Diede and Gottschling 2001) and UCC5114 (Stellwagen et al. 2003) were used in the de novo telomere addition experiment, as were strains YJA012 and YJA014 that were created by two-step gene replacement of UCC6073 using plasmids pJA002 and pJA004. Strain UCC5114 (Stellwagen et al. 2003) was used in the GCR assay along with strains YED001, YED003, and YED005, in which tlc1 $\Delta 48$,

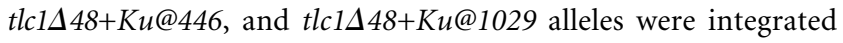
into BY4727 (Brachmann et al. 1998) by two-step gene replacement using plasmids pJA002 and pJA004, and URA3 was inserted distal to CAN1 by PCR-mediated gene disruption of the HXT13 locus.

To test phenotypes for each allele of TLC1 present on CEN plasmids, transformants were streaked on -Trp medium 10 times to assess growth and screen for senescence. In Southern blotting experiments showing 50-70 generations, cells were grown in liquid culture inoculated from a single colony off the first -Trp plate subsequent to the $-\operatorname{Trp}+\alpha$-aminoadipate used for shuffling 
out the pTLC1(LYS2) wild-type cover plasmid. For Southerns indicating 300-generation time courses, genomic DNA was isolated from 20-mL - Trp cultures each set from a single colony from the first, fourth, seventh, and tenth - Trp restreak plate after the TLC1 plasmid-shuffle.

\section{Telomeric silencing assay}

UCC3505 was transformed with the indicated TRP1-marked plasmids that drive the overexpression of TLC1 alleles via the GAL1 promoter. Liquid cultures of each strain were then grown, and 10 -fold serial dilutions of each were applied to -Trp media containing 3\% galactose to evaluate colony color and number and to -Trp -Ura media containing 3\% galactose to monitor expression of the telomeric URA3 reporter gene.

\section{Yeast culturing for nucleic acid blots}

Southern blotting of yeast genomic DNA was performed as previously described (Friedman and Cech 1999; Zappulla et al. 2005). Briefly, in cases where 10-generation increments are shown, cells were passaged by serially diluting $20-\mathrm{mL}$ saturated cultures 1028 -fold $\left(1 \times 2^{10}\right.$ or 10 generations $)$ daily or, in all other cases, by setting cultures from serially restreaked plates, where each restreak was treated as 30 generations. Pelleted cells from cultures were frozen at $-80^{\circ} \mathrm{C}$, and genomic DNA was then isolated using the Gentra Puregene system, quantitated by running a small amount on an ethidium bromide-stained agarose gel and subjecting this to Imagequant software analysis after direct scanning on a PhosphorImager (GE Healthcare). Equal amounts of DNA were then digested for at least $2 \mathrm{~h}$ with XhoI and electrophoresed through a $1.1 \%$ agarose gel for $17 \mathrm{~h}$ at $70 \mathrm{~V}$, nicked, denatured, and transferred to Hybond-N+ Nylon membrane (GE). After cross-linking, DNA was hybridized to a telomeric probe (both G- and C-rich strands) as well as a 1627-bp Chr IV fragment (Friedman and Cech 1999), and then scanned on a PhosphorImager and analyzed using Imagequant TL Software (GE Healthcare).

Northern blotting was performed from electrophoresis using $1.5-\mathrm{mm}$ thick vertical polyacrylamide gels as described (Zappulla et al. 2005), except that probes were used for TLC1 (the 1012-bp fragment from StuI-NsiI) and U1 snRNA (Friedman and Cech 1999). Hybridization was performed with $1-5 \times 10^{4} \mathrm{cpm} / \mathrm{mL}$ of $\mathrm{U} 1$ probe and $1 \times 10^{6} \mathrm{cpm} / \mathrm{mL}$ for the less abundant TLC1 RNA.

\section{Quantification of telomere length}

Given that just more than half of yeast telomeres (17 of 32 in a haploid) contain subtelomeric $\mathrm{Y}^{\prime}$ sequence elements and there is an XhoI restriction site in this region, this group of telomeres is useful for monitoring telomere length by XhoI digestion and Southern blotting with a telomeric probe. However, the distribution of these telomeric restriction fragments is not Gaussian even in wild-type cells and, therefore, using the peak of the signal (i.e., the statistical mode) over this range on the blot is also not the average and in many situations can be highly inaccurate. Therefore, we developed a weighted average mobility (WAM) assay for $\mathrm{Y}^{\prime}$ telomere lengths so that we could determine the telomere length supported by the TLC1 alleles with repositioned $\mathrm{Ku}$ sites. We subjected 10 telomere Southern blots to our WAM analysis method, summarized as follows. Using Imagequant 5.2 (GE Healthcare), an identical line was laid over the entirety of each lane of the blots (including a polynucleotide kinase-labeled $\varphi$ X174-HaeIII and a $\lambda$-HindIII marker, or in a few cases, a 1-kb ladder). The lines were aligned horizontally, then were all selected and raw data extracted by copying and pasting them to a spreadsheet. Next, the relative mobility was normalized across the lanes by using the Pixel Inspector in Imagequant 5.2 to identify a position precisely below the y-coordinate of the chromosome IV (Chr IV) nontelomeric control fragment by centering the top of the "+" crosshair with the bottom edge of this sharp band. This was repeated evenly for all lanes. The position just below this 1627-bp band was used as the upper boundary of the $\mathrm{Y}^{\prime}$ fragments. To define the minimal boundary, a $y$-axis value for a position further down the gel than the $\mathrm{Y}^{\prime}$ signal from a $t l c 1$ mutant was identified with the Pixel Inspector (typically $\sim 900 \mathrm{bp}$ ). The relative fluorescent units ( $\mathrm{rfu}$ ) for each $y$-axis set of pixels through the range of the $\mathrm{Y}^{\prime}$ fragment region (or $\sim 900-1600 \mathrm{bp}$ ), normalized to the relative mobility of the nontelomeric fragment, was then copied to a new spreadsheet for each lane. At this point, the minimal rfu value within the range (which toward the bottom of the gel contains no telomere signal) was set as background (bkg) and subtracted from rfu data for each $y$-axis pixel position. The background-subtracted telomeric fragment intensity was then multiplied by the pixel number ( 1 pixel = $0.1 \mathrm{~mm}$ ) through the range, and these products were summed and then divided by the sum of the background-subtracted rfu alone to generate the weighted average relative mobility, $\bar{y}_{w}$, as summarized by the following equation:

$$
\bar{y}_{w}=\frac{\sum_{\sim 900 b p}^{\sim 1600 b p} y(r f u-b k g)}{\sum_{\sim 900 b p}^{\sim 1600 b p}(r f u-b k g)}
$$

This $\bar{y}_{w}$ relative mobility weighted mean value for $\mathrm{Y}^{\prime}$ telomeres in each lane was then converted to base pairs using an exponential formula expression for the relative mobility of prelabeled DNA molecular mass markers using Kaleidagraph software (Synergy; $\mathrm{R}^{2}$ fits ranged from 0.998 to 1.0 for all 10 blots). Since the marker was always loaded adjacent to the left-most lane of each gel, any distortions in relative mobility across the gel are already normalized, since $\bar{y}_{w}$ for $\mathrm{Y}^{\prime}$ telomeres is already adjusted to the mobility of the nontelomeric 1627-bp chromosome IV relative mobility control fragment.

Once the WAM assay-derived $\mathrm{Y}^{\prime}$ telomere length was established for each generational time point, those for each group were averaged. The same generations were studied in a given experiment except for $t l c 1 \Delta$ alleles, which senesced before 100 generations. Experiments typically included three or four time points between 50 and 300 generations; i.e., cells from a liquid culture set from a TLC1 plasmid allele transformant struck out sequentially on solid medium 10 times, based on an estimate of 30 generations per colony.

\section{De novo telomere addition assay}

De novo telomere addition assays were performed as previously described (Diede and Gottschling 1999). In brief, log-phase cells 
were arrested with nocodazole and then shifted into YEP $+3 \%$ galactose + nocodazole. Time points were collected hourly. DNA was harvested, digested with SpeI, and analyzed by Southern blot using an $A D E 2$ probe.

\section{Gross chromosomal rearrangements assays}

GCR assays were performed essentially as described (Stellwagen et al. 2003). Log-phase yeast were treated with 0.04\% MMS for an hour to induce DNA damage, allowed to recover, and then plated on media containing canavanine and 5-FOA and on YEPD to determine GCR frequencies.

\section{SUPPLEMENTAL MATERIAL}

Supplemental material can be found at http://www.rnajournal.org.

\section{ACKNOWLEDGMENTS}

We thank Dan Gottschling for his help and for strain UCC6078-1, Maryann Salib for assistance with constructing derivative strain MSy24, Rebecca Sherwood for assistance in constructing strains YED001-005, and Robert F. Schleif for helpful suggestions. This work was supported by NIH grant GM28039 to T.R.C. as well as initiated with NIH funding from K99 GM80400 to D.C.Z. (at the University of Colorado) and completed with funding to D.C.Z. from R00 GM80400 at Johns Hopkins University. The contents are solely the responsibility of the authors and do not necessarily represent the official views of the National Institute of General Medical Sciences.

Received October 6, 2010; accepted November 15, 2010.

\section{REFERENCES}

Bianchi A, Negrini S, Shore D. 2004. Delivery of yeast telomerase to a DNA break depends on the recruitment functions of $\mathrm{Cdc} 13$ and Est1. Mol Cell 16: 139-146.

Boulton SJ, Jackson SP. 1996. Saccharomyces cerevisiae Ku70 potentiates illegitimate DNA double-strand break repair and serves as a barrier to error-prone DNA repair pathways. EMBO J 15: 5093 5103.

Brachmann CB, Davies A, Cost GJ, Caputo E, Li J, Hieter P, Boeke JD. 1998. Designer deletion strains derived from Saccharomyces cerevisiae S288C: A useful set of strains and plasmids for PCR-mediated gene disruption and other applications. Yeast 14: 115-132.

Cech TR. 2004. Beginning to understand the end of the chromosome. Cell 116: 273-279.

Chappell AS, Lundblad V. 2004. Structural elements required for association of the Saccharomyces cerevisiae telomerase RNA with the Est2 reverse transcriptase. Mol Cell Biol 24: 7720-7736.

Dandjinou AT, Levesque N, Larose S, Lucier JF, Abou Elela S, Wellinger RJ. 2004. A phylogenetically based secondary structure for the yeast telomerase RNA. Curr Biol 14: 1148-1158.

Diede SJ, Gottschling DE. 1999. Telomerase-mediated telomere addition in vivo requires DNA primase and DNA polymerases $\alpha$ and $\delta$. Cell 99: 723-733.

Diede SJ, Gottschling DE. 2001. Exonuclease activity is required for sequence addition and Cdc13p loading at a de novo telomere. Curr Biol 11: 1336-1340.

Eldridge AM, Halsey WA, Wuttke DS. 2006. Identification of the determinants for the specific recognition of single-strand telomeric DNA by Cdc13. Biochemistry 45: 871-879.
Evans SK, Lundblad V. 2002. The Est1 subunit of Saccharomyces cerevisiae telomerase makes multiple contributions to telomere length maintenance. Genetics 162: 1101-1115.

Feldmann H, Winnacker EL. 1993. A putative homologue of the human autoantigen Ku from Saccharomyces cerevisiae. J Biol Chem 268: 12895-12900.

Feldmann H, Driller L, Meier B, Mages G, Kellermann J, Winnacker EL. 1996. HDF2, the second subunit of the Ku homologue from Saccharomyces cerevisiae. J Biol Chem 271: 27765-27769.

Fisher TS, Zakian VA. 2005. Ku: A multifunctional protein involved in telomere maintenance. DNA Repair (Amst) 4: 1215-1226.

Fisher TS, Taggart AK, Zakian VA. 2004. Cell cycle-dependent regulation of yeast telomerase by Ku. Nat Struct Mol Biol 11: $1198-1205$.

Friedman KL, Cech TR. 1999. Essential functions of amino-terminal domains in the yeast telomerase catalytic subunit revealed by selection for viable mutants. Genes Dev 13: 2863-2874.

Gallardo F, Olivier C, Dandjinou AT, Wellinger RJ, Chartrand P. 2008. TLC1 RNA nucleo-cytoplasmic trafficking links telomerase biogenesis to its recruitment to telomeres. EMBO J 27: 748757.

Gravel S, Larrivee M, Labrecque P, Wellinger RJ. 1998. Yeast Ku as a regulator of chromosomal DNA end structure. Science 280: 741744.

Greider CW, Blackburn EH. 1989. A telomeric sequence in the RNA of Tetrahymena telomerase required for telomere repeat synthesis. Nature 337: 331-337.

Igel AH, Ares M Jr. 1988. Internal sequences that distinguish yeast from metazoan U2 snRNA are unnecessary for pre-mRNA splicing. Nature 334: 450-453.

Kretzner L, Rymond BC, Rosbash M. 1987. S. cerevisiae U1 RNA is large and has limited primary sequence homology to metazoan U1 snRNA. Cell 50: 593-602.

Lin J, Ly H, Hussain A, Abraham M, Pearl S, Tzfati Y, Parslow TG, Blackburn EH. 2004. A universal telomerase RNA core structure includes structured motifs required for binding the telomerase reverse transcriptase protein. Proc Natl Acad Sci 101: 1471314718.

Lingner J, Cooper JP, Cech TR. 1995. Telomerase and DNA end replication: No longer a lagging strand problem? Science 269: $1533-1534$

Livengood AJ, Zaug AJ, Cech TR. 2002. Essential regions of Saccharomyces cerevisiae telomerase RNA: Separate elements for Est1p and Est2p interaction. Mol Cell Biol 22: 2366-2374.

Luger K, Mader AW, Richmond RK, Sargent DF, Richmond TJ. 1997. Crystal structure of the nucleosome core particle at $2.8 \mathrm{~A}$ resolution. Nature 389: 251-260.

Mathews DH, Sabina J, Zuker M, Turner DH. 1999. Expanded sequence dependence of thermodynamic parameters improves prediction of RNA secondary structure. J Mol Biol 288: 911-940.

Mimori T, Hardin JA. 1986. Mechanism of interaction between $\mathrm{Ku}$ protein and DNA. J Biol Chem 261: 10375-10379.

Moore PB, Steitz TA. 2002. The involvement of RNA in ribosome function. Nature 418: 229-235.

Mozdy AD, Cech TR. 2006. Low abundance of telomerase in yeast: Implications for telomerase haploinsufficiency. RNA 12: 1721-1737.

Mozdy AD, Podell ER, Cech TR. 2008. Multiple yeast genes, including Paf1 complex genes, affect telomere length via telomerase RNA abundance. Mol Cell Biol 28: 4152-4161.

Myung K, Chen C, Kolodner RD. 2001. Multiple pathways cooperate in the suppression of genome instability in Saccharomyces cerevisiae. Nature 411: 1073-1076.

Olovnikov AM. 1973. A theory of marginotomy. The incomplete copying of template margin in enzymic synthesis of polynucleotides and biological significance of the phenomenon. J Theor Biol 41: $181-190$.

Pennaneach V, Putnam CD, Kolodner RD. 2006. Chromosome healing by de novo telomere addition in Saccharomyces cerevisiae. Mol Microbiol 59: 1357-1368. 
Peterson SE, Stellwagen AE, Diede SJ, Singer MS, Haimberger ZW, Johnson CO, Tzoneva M, Gottschling DE. 2001. The function of a stem-loop in telomerase RNA is linked to the DNA repair protein Ku. Nat Genet 27: 64-67.

Qiao F, Cech TR. 2008. Triple-helix structure in telomerase RNA contributes to catalysis. Nat Struct Mol Biol 15: 634-640.

Seto AG, Livengood AJ, Tzfati Y, Blackburn EH, Cech TR. 2002. A bulged stem tethers Estlp to telomerase RNA in budding yeasts. Genes Dev 16: 2800-2810.

Shuster EO, Guthrie C. 1988. Two conserved domains of yeast U2 snRNA are separated by 945 nonessential nucleotides. Cell 55: 41-48.

Siliciano PG, Kivens WJ, Guthrie C. 1991. More than half of yeast U1 snRNA is dispensable for growth. Nucleic Acids Res 19: 6367-6372.

Singer MS, Gottschling DE. 1994. TLC1: Template RNA component of Saccharomyces cerevisiae telomerase. Science 266: 404-409.

Singer MS, Kahana A, Wolf AJ, Meisinger LL, Peterson SE, Goggin C, Mahowald M, Gottschling DE. 1998. Identification of high-copy disruptors of telomeric silencing in Saccharomyces cerevisiae. Genetics 150: 613-632.

Stellwagen AE, Haimberger ZW, Veatch JR, Gottschling DE. 2003. $\mathrm{Ku}$ interacts with telomerase RNA to promote telomere addition at native and broken chromosome ends. Genes Dev 17: 23842395.

Theimer CA, Blois CA, Feigon J. 2005. Structure of the human telomerase RNA pseudoknot reveals conserved tertiary interactions essential for function. Mol Cell 17: 671-682.

Ting NS, Yu Y, Pohorelic B, Lees-Miller SP, Beattie TL. 2005. Human $\mathrm{Ku} 70 / 80$ interacts directly with hTR, the RNA component of human telomerase. Nucleic Acids Res 33: 2090-2098.
Tuteja R, Tuteja N. 2000. Ku autoantigen: A multifunctional DNAbinding protein. Crit Rev Biochem Mol Biol 35: 1-33.

Tzfati Y, Knight Z, Roy J, Blackburn EH. 2003. A novel pseudoknot element is essential for the action of a yeast telomerase. Genes Dev 17: 1779-1788.

Walker JR, Corpina RA, Goldberg J. 2001. Structure of the Ku heterodimer bound to DNA and its implications for double-strand break repair. Nature 412: 607-614.

Wang F, Podell ER, Zaug AJ, Yang Y, Baciu P, Cech TR, Lei M. 2007. The POT1-TPP1 telomere complex is a telomerase processivity factor. Nature 445: 506-510.

Watson JD. 1972. Origin of concatemeric T7 DNA. Nat New Biol 239: 197-201.

Wong JM, Collins K. 2006. Telomerase RNA level limits telomere maintenance in X-linked dyskeratosis congenita. Genes Dev 20: 2848-2858.

Zappulla DC, Cech TR. 2004. Yeast telomerase RNA: A flexible scaffold for protein subunits. Proc Natl Acad Sci 101: 10024-10029.

Zappulla DC, Cech TR. 2006. RNA as a flexible scaffold for proteins: Yeast telomerase and beyond. Cold Spring Harb Symp Quant Biol 71: 217-224.

Zappulla DC, Goodrich K, Cech TR. 2005. A miniature yeast telomerase RNA functions in vivo and reconstitutes activity in vitro. Nat Struct Mol Biol 12: 1072-1077.

Zhang W, Durocher D. 2010. De novo telomere formation is suppressed by the Mec1-dependent inhibition of Cdc13 accumulation at DNA breaks. Genes Dev 24: 502-515.

Zuker M. 2003. Mfold web server for nucleic acid folding and hybridization prediction. Nucleic Acids Res 31: 3406-3415. 

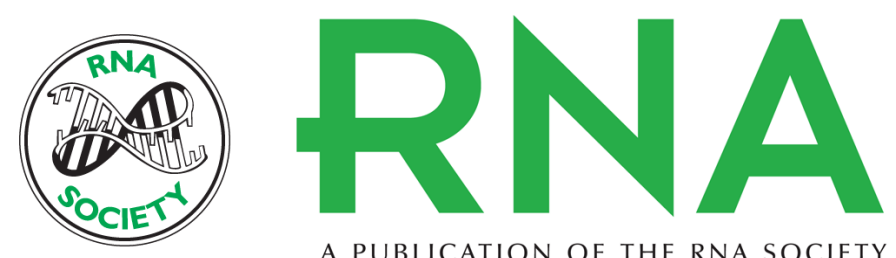

A PUBLICATION OF THE RNA SOCIETY

\section{Ku can contribute to telomere lengthening in yeast at multiple positions in the telomerase RNP}

David C. Zappulla, Karen J. Goodrich, Julian R. Arthur, et al.

RNA 2011 17: 298-311 originally published online December 21, 2010

Access the most recent version at doi:10.1261/rna.2483611

Supplemental
Material http://rnajournal.cshlp.org/content/suppl/2010/12/07/rna.2483611.DC1

References This article cites 53 articles, 19 of which can be accessed free at:

http://rnajournal.cshlp.org/content/17/2/298.full.html\#ref-list-1

License

Email Alerting Receive free email alerts when new articles cite this article - sign up in the box at the Service top right corner of the article or click here. 